\title{
Only two out of five articles by New Zealand researchers are free-to-access: a multiple API study of access, citations, cost of Article Processing Charges (APC), and the potential to increase the proportion of open access
} \author{
Emma Richardson ${ }^{6}$, Bruce White \\ ${ }^{1}$ Vice-Chancellor's Office, University of Otago, Otago, New Zealand \\ 2 Library, University of Canterbury, Christchurch, New Zealand \\ 3 Learning, Teaching and Library, Lincoln University, Lincoln, New Zealand \\ 4 Library, Auckland University of Technology, Auckland, New Zealand \\ 5 Library, University of Waikato, Hamilton, New Zealand \\ 6 Libraries and Learning Services, University of Auckland, Auckland, New Zealand \\ 7 Office of the Provost, Massey University, Palmerston North, New Zealand \\ Corresponding Author: Richard K A White \\ Email address: richard.white@otago.ac.nz
}

Richard K A White ${ }^{\text {Corresp., } 1}$, Anton Angelo ${ }^{2}$, Deborah Fitchett ${ }^{3}$, Moira Fraser ${ }^{2}$, Luqman Hayes $^{4}$, Jessica Howie ${ }^{5}$,

We studied journal articles published by researchers at all eight of New Zealand universities in 2017 to determine how many were freely accessible on the web. We wrote software code to harvest data from multiple sources, code that we now share to enable others to reproduce our work on their own sample set. In May 2019, we ran our code to determine which of the 2017 articles were open at that time and by what method; where those articles would have incurred an Article Processing Charge (APC) we calculated the cost if those charges had been paid. Where articles were not freely available we determined whether the policies of publishers in each case would have allowed deposit in a non-commercial repository (Green open access). We also examined citation rates for different types of access. We found that, of our 2017 sample set, about two out of every five articles were freely accessible without payment or subscription (41\%). Where research was explicitly said to be funded by New Zealand's major research funding agencies, the proportion was slightly higher at $45 \%$. Where open articles would have incurred an APC we estimated an average cost per article of USD1,682 (for publications where all articles require an APC, that is, Gold open access) and USD2,558 (where APC payment is optional, Hybrid open access) at a total estimated cost of USD1.45m. Of the paid options, Gold is by far more common for New Zealand researchers ( $82 \%$ Gold, $18 \%$ Hybrid). In terms of citations, our analysis aligned with previous studies that suggest a correlation between publications being freely accessible and, on balance, slightly higher rates of citation. This 
is not seen across all types of open access, however, with Diamond OA achieving the lowest rates. Where articles were not freely accessible we found that a very large majority of them (88\% or 3089 publications) could have been legally deposited in an institutional repository. Similarly, only in a very small number of cases had a version deposited in the repository of a New Zealand university made the difference between the publication being freely accessible or not (125 publications). Given that most New Zealand researchers support research being open, there is clearly a large gap between belief and practice in New Zealand's research ecosystem. 
1 Only two out of five articles by New Zealand researchers are free-to-access: a multiple API

2 study of access, citations, cost of Article Processing Charges (APC), and the potential to increase

3 the proportion of open access

4

5 Richard Kenneth Alistair White ${ }^{1}$, Anton Angelo ${ }^{2}$, Deborah Jane Fitchett ${ }^{3}$, Moira Fraser ${ }^{4}$, Luqman Hayes $^{5}$, Jess Howie ${ }^{6}$, Emma Richardson ${ }^{7}$, Bruce Duncan White ${ }^{8}$

${ }^{1}$ Vice-Chancellor's Office, University of Otago, Dunedin, Otago, Aotearoa New Zealand

${ }^{2}$ Library, University of Canterbury, Christchurch, Canterbury, Aotearoa New Zealand

${ }^{3}$ Learning, Teaching \& Library, Lincoln University, Lincoln, Canterbury, Aotearoa New Zealand

${ }^{4}$ Library, University of Canterbury, Christchurch, Canterbury, Aotearoa New Zealand

${ }^{5}$ Library, Auckland University of Technology, Auckland, Auckland, Aotearoa New Zealand

${ }^{6}$ Library, University of Waikato, Hamilton, Waikato, Aotearoa New Zealand Zealand Zealand

Corresponding Author:

Richard White ${ }^{1}$

Email address: richard.white@,otago.ac.nz

\section{Abstract}

We studied journal articles published by researchers at all eight of New Zealand universities in 2017 to determine how many were freely accessible on the web. We wrote software code to harvest data from multiple sources, code that we now share to enable others to reproduce our work on their own sample set. In May 2019, we ran our code to determine which of the 2017 articles were open at that time and by what method; where those articles would have incurred an Article Processing Charge (APC) we calculated the cost if those charges had been paid. Where articles were not freely available we determined whether the policies of publishers in each case would have allowed deposit in a non-commercial repository (Green open access). We also examined citation rates for different types of access. We found that, of our 2017 sample set, about two out of every five articles were freely accessible without payment or subscription (41\%). Where research was explicitly said to be funded by New Zealand's major research funding agencies, the proportion was slightly higher at $45 \%$. Where open articles would have incurred an APC we estimated an average cost per article of USD1,682 (for publications where all articles require an APC, that is, Gold open access) and USD2,558 (where APC payment is 
optional, Hybrid open access) at a total estimated cost of USD1.45m. Of the paid options, Gold is by far more common for New Zealand researchers ( $82 \%$ Gold, 18\% Hybrid). In terms of citations, our analysis aligned with previous studies that suggest a correlation between publications being freely accessible and, on balance, slightly higher rates of citation. This is not seen across all types of open access, however, with Diamond OA achieving the lowest rates. Where articles were not freely accessible we found that a very large majority of them $(88 \%$ or 3089 publications) could have been legally deposited in an institutional repository. Similarly, only in a very small number of cases had a version deposited in the repository of a New Zealand university made the difference between the publication being freely accessible or not (125 publications). Given that most New Zealand researchers support research being open, there is clearly a large gap between belief and practice in New Zealand's research ecosystem.

\section{Introduction}

Researchers seek to change the world and writers seek to be read, but for many years a dysfunctional scholarly publishing system has walled off most published research findings from the majority of its potential readership. Since the transition from print to electronic publishing began in the late $1990 \mathrm{~s}$, various initiatives explored the potential for this digital transformation to make research literature more accessible to the public. University libraries, concerned about continuing growth in journal subscription costs, hoped an open access system would provide a more affordable alternative. At the same time they sought to advance the mission of their host institutions to create social capital through the promulgation of quality peer-reviewed research.

Three major developments in the early 2000s set the scene for the current open access environment:

- The growth of "Gold open access" journals, funded by Article Processing Charges (APCs) rather than by subscriptions.

- The adoption of "Hybrid open access" options by subscription journals, making individual papers openly accessible through the payment of APCs.

- The growth of institutional and subject-specific repositories, providing an alternative route of "Green open access" to individual papers without publication charges.

Since then there has been considerable interest in the potential of open access to contribute to universities' own goals as a result of supporting broader society to access research outputs. This includes a growing understanding that, as a result of their enhanced availability, openly accessible papers are likely to be cited at a higher rate than those behind paywalls.

Unfortunately, open access has not produced the anticipated reduction in costs. Subscription costs of research journals continue to rise while APCs for Gold and Hybrid journals add another 
77 cost to university budgets (Guédon et al. 2019). Furthermore, whereas subscription costs were centralised within library budgets, APC charges are paid from a variety of sources, including 79 departmental budgets and external research funds, which makes them less visible and harder to 80 manage (Monaghan et al. 2020). Moreover libraries have had limited success in encouraging 81 researchers to deposit copies of their work in institutional repositories. In New Zealand, this is 82 despite all universities having an institutional repository. The emergence of transformative 83 agreements has also been a significant development. These agreements vary, but at their core 84 they share the goal of shifting from subscription-based reading to contractually-based publishing. 85 Although transformative agreements are becoming more common, they are still only a factor for 86 a small number of institutions and their development is outside of the scope of this research.

New Zealand has no specific guidance from government or major research funding agencies on open access publishing or centralised support to pay APCs. While government has established an open access framework that applies to government agencies, this does not extend to the university sector (New Zealand Government 2014). A recent government consultation document on research strategy raised the possibility that a co-ordinated approach in the research sector could be of benefit. ${ }^{1}$ To date, New Zealand's major funding agencies have not enforced requirements on research projects they fund to release research outputs or data with open licences. Some New Zealand universities have adopted open access policies and/or guidelines following the Green open access pathway (Wikipedia contributors 2020), as there is no government funding to enable Gold open access. Three universities operate small APC funds to

In 2019 the Council for New Zealand University Libraries (CONZUL) established a project team with representatives from seven of the eight New Zealand universities to research the current environment of open access in New Zealand. A major stream of this project sought to establish how much of our universities' research outputs were open access. While other tools provide a figure for the proportion of research that is open, we wanted to extend our understanding to determine:

106

- how much our researchers might be spending on Article Processing Charges (APCs) on top of what libraries pay in subscriptions;

- how much of our work could be freely accessible via self-archiving but is not; and

- the relationship between openness and citations or other measures of impact. 
115 This paper focuses on one element of the CONZUL Open Access Project. The wider project

116 produced a full report (Fraser et al. 2019) examining the wider open access environment in New

117 Zealand and an infographic designed to communicate its findings in a readily digestible format.

\section{Literature Review}

119 As the prevalence of open access publication of research results has increased over the years

120 (Abediyarandi \& Mayr 2019; Archambault et al. 2014; Archambault et al. 2013; Gargouri et al.

121 2010; Laakso et al. 2011; Maddi 2019; Martín-Martín et al. 2018; Piwowar et al. 2018; Wang et

122 al. 2018), so too has the ability to gain insight into its nature and development. However, this has

123 occurred alongside increasing complexity in the way open access levels are measured, and the

124 resulting literature is methodologically diverse. A recent publication highlighted the need for

125 critical reflection on the methods employed to measure open access development in order to

126 address regional and political inequity (Huang et al. 2020). This literature review presents a brief

127 overview of the main methodological approaches and relevant results.

128

129 Perhaps the most influential study in recent years was carried out by Piwowar et al. (2018). In

130 their review of the literature, they note the paucity of studies between 2014 and the time of

131 writing, however further large-scale studies quickly followed (Robinson-Garcia et al. 2020;

132 Huang et al. (2020). As more automated research on open access becomes possible through

133 Application Programming Interfaces (APIs) and enhanced indexing, sample sizes have increased

134 (Piwowar et al. 2018). How open access development is measured depends on a number of

135 factors, including scope and source of data. Different methods are used according to the aims of

136 the research. Some studies focus on a given country (Abediyarandi \& Mayr 2019; Bosman \&

137 Kramer 2019; Holmberg et al. 2019; Mikki et al. 2018; Piryani et al. 2019; Pölönen et al. 2019;

138 Sivertsen et al. 2019) open access type (Wang et al. 2018) or funder (Kirkman 2018). Others aim

139 for a global overview (Archambault et al. 2014; Laakso et al. 2011; Martín-Martín et al. 2018;

140 Piwowar et al. 2018; Robinson-Garcia et al. 2020 Wang et al. 2018).

141

142 Because of this diversity, it is difficult to draw comparisons between results. Most recent studies

143 point to an overall open access rate of between 45 and 55\% (Bosman \& Kramer 2019; Martín-

144 Martín et al. 2018; Piwowar et al. 2018; Pölönen et al. 2019). This is significant because an open

145 access rate of $50 \%$ is posited as a "tipping point" by some (Archambault et al. 2013). Where

146 open access rate is calculated as total of the scholarly record or over an extended period, this

147 figure drops dramatically - Piwowar et al. (2018) estimate the total percent of scholarly record at

$14828 \%$, Maddi (2019) at 31\%. Piwowar et al. (2019) hypothesize a rise to $44 \%$ by 2025 . Where

149 wider sources are included, such as Academic Social Networks (ASNs) or Google Scholar the

150 open access rate rises (Martín-Martín et al. 2018; Nazim \& Zia 2019). Unsurprisingly, older

151 studies report lower rates (Bjork et al. 2010; Gargouri et al. 2010), reinforcing the findings of

152 many scholars that open access is on the rise (Abediyarandi \& Mayr 2019; Archambault et al. 
153 2014; Archambault et al. 2013; Gargouri et al. 2010; Laakso et al. 2011; Maddi 2019; Martín154 Martín et al. 2018; Piwowar et al. 2018; Wang et al. 2018). The growth of Gold open access in 155 particular has been noted (Archambault et al. 2014; Martín-Martín et al. 2018; Piryani et al. 156 2019; Pölönen et al. 2019). Despite this, the literature clearly shows that open access

157 development varies by discipline (Bjork et al. 2010; Bosman \& Kramer 2019; Maddi 2019;

158 Martín-Martín et al. 2018; Piryani et al. 2019; Robinson-Garcia et al. 2020; Sivertsen et al. 2019)

159 and country (Archambault et al. 2014; Maddi 2019; Martín-Martín et al. 2018; Robinson-Garcia

160 et al. 2020 Sivertsen et al. 2019; Torres-Salinas et al. 2019; Wang et al. 2018).

161

162 It is important to note that all of these results can only be viewed as accurate at a given point of 163 time. Both Archambault et al. (2014) and Robinson-Garcia et al. (2020) point out that freely

164 accessible research does not always adhere to the tenets of "open access". Open access is fluid in 165 nature - closed articles can become open after embargoes, repositories can be backfilled and 166 publications may be open access but only at the discretion of the publisher or on limited terms

167 This is manifest in the fact that Piwowar et al. (2018) introduced the Bronze category, defined as

168 "made free-to-read on the publisher website, without an explicitly open license". They noted that

169 "It is also not clear if Bronze articles are temporarily or permanently available to read for free"

170 (p.6). In fact, there is limited consensus on the definition of all open access types and even on the

171 line between open access and non-open access. Similarly, the results of any study are also

172 closely linked to its scope and source data - many studies use Web of Science or Scopus, which

173 are known to under-represent certain areas of literature (Martín-Martín et al. 2018). As

174 automation becomes more central to open access research, results become limited to those

175 publications with a DOI, further excluding some important categories of research. Robinson-

176 Garcia et al. (2019) argued that sources of open access status such as Unpaywall also need to be

177 better understood in order to fairly represent open access rates.

The funding of open access through article processing charges (APCs) is another matter of high concern, although there is limited consensus in the literature around how these costs are to be estimated. A journal is classified as Gold if all articles are immediately open and APCs for these titles are recorded in the Directory of Open Access Journals (DOAJ), while for Hybrid journals the articles are paywalled unless an APC is charged. One method of estimating the cost of APCs to institutions is by examining financial records (Jahn \& Tullney 2016; Pinfield et al. 2017; Solomon \& Björk 2016) which aims to capture the actual amounts paid or by reviewing institutional agreements with publishers (Lovén 2019). The other main approach is capturing the advertised prices from DOAJ or publisher websites (Björk \& Solomon 2015; Matthias 2018; Morrison et al. 2016; Solomon \& Björk 2016).

Citation advantage is another topic that has been hotly debated in the literature. Research almost always finds a positive correlation between open access and citation rate (Archambault et al. 2014; Copiello 2019; McCabe \& Snyder 2014; Mikki et al. 2018; Ottaviani 2016; Piwowar et al. 
193 2018; Piwowar et al. 2019; Wang et al. 2015). However confounding factors cast considerable 194 uncertainty over direct causation (Gaulé \& Maystre 2011; Torres-Salinas et al. 2019). It is also 195 clear that citation advantage is not distributed evenly across all disciplines (Holmberg et al.

196 2019) or types of open access (Mikki et al. 2018; Piwowar et al. 2018). In fact, several studies

197 have found a citation disadvantage for Gold open access (Archambault et al. 2014; Archambault

198 et al. 2013; Piwowar et al. 2018; Torres-Salinas et al. 2019). The way citation advantage (or lack 199 thereof) is measured can have a considerable influence on results, leading some scholars to use 200 normalised figures such as Category Normalised Citation Impact (Torres-Salinas et al. 2019) or Average Relative Citation (Archambault et al. 2016) rather than total citations. Others argue that

202 quality bias from self-selection (i.e., researchers select open access for higher quality work)

203 inflate the apparent citation advantage (Torres-Salinas et al. 2019). However, some authors have found that a citation advantage exists despite confounding factors, albeit at a lower rate

205 (Gargouri et al. 2010; McCabe \& Snyder 2014; Ottaviani 2016). Attention, as measured by views, downloads and altmetrics, are similarly positively affected (Adie 2014; Holmberg et al. 2019; Wang et al. 2015) and Wang et al. (2015) found that downloads for open access publications were sustained for longer periods of time than non-open access. On balance, the literature largely confirms the open access citation advantage but the magnitude and reasons for this remain unclear.

\section{Materials \& Methods}

212 The CONZUL project team developed software that used Digital Object Identifiers (DOIs) to 213 establish publications' open access status, APC price, and ability to be self-archived.

214

215 Our work depended on many open API services, the most integral being Unpaywall. As such our 216 definition of 'open' in this study largely aligns with that of Unpaywall, including Bronze as

217 initially proposed by Piwowar et al. (2018). Thus the openness of an article in our study is

218 defined very broadly: "OA articles are free to read online, either on the publisher website or in an

219 OA repository." Unpaywall does "not harvest from sources of dubious legality like

220 ResearchGate or Sci-Hub" (Unpaywall). Table 1 shows the categories we used and an associated 221 definition.

222

223

224

225

226

227

228

229

230

Unpaywall uses a hierarchy to determine a single status for each paper. Priority is given to those statuses which imply immutability, specifically through publication in a Gold journal or through the payment of an APC in a Hybrid journal. For Gold journals no distinction is made between those that charge APCs and those that do not, following the definition of Gold as any form of open publication regardless of business model, as offered by Suber (2012). In our study, we were particularly interested in distinguishing between paid and unpaid forms of OA. Therefore, where the Directory of Open Access Journals (DOAJ) showed a Gold journal does not charge APCs, we re-categorised these as Diamond. This means we use the term 'Gold' in this paper exclusively 
231 to mean publication in an OA-only journal where an APC is charged. As already noted,

232 Unpaywall introduced the Bronze status for papers openly available from the publishers but

233 without an explicit license. Perhaps unfortunately, given questions around the persistence of

234 Bronze open access, this status was given a higher priority than Green, which was reserved for

235 papers openly accessible from repositories rather than from publishers. In this paper we use

236 Green with the specific meaning that a publication has been made available in a reputable

237 repository and that this is the only open version. Thus, while there may be overlap between

238 categories, each publication is only given a single type of OA: for example, a paper may have

239 been published in a Hybrid journal and deposited by a researcher in a repository; since the

240 published version is 'better' according to the Unpaywall hierarchy, this is classified as Hybrid

241 not Green. The status Closed is defined as papers that are not openly available in any form.

242

243

244

245

246

247

248

249

250

251

252

253

254

255

256

257

258

259

260

261

262

263

264

265

266

267

268

269

Piwowar et al (2018) found that under the version of the API running in 2018 found that $77 \%$ of all papers identified as open by a manual accuracy check were correctly identified as such and that $96 \%$ of the papers identified as open by the API were in fact open. The main variations are likely to occur from repository copies not being identified and Bronze papers reverting to Closed status over time. The Unpaywall API is widely used and provides robust comparability with other studies.

Overlaying the access dimension is the question of authorship. The number of authors of a published research article can range from one (sole authorship) to several thousand (project participation). Multiple authorship is a significant issue when we attempt to link published research to institutions and countries, particularly when there are no established norms for allocating divisions of responsibility. Where there are, say, 200 authors in a research group the fact that one of them is employed at University A tells us very little about the behaviour and performance of that institution, although a productive project may end up crediting it with numerous publications on the basis of participation by this single team member. This may be an insoluble problem for affiliation-based bibliometric research but in a project like the present one it is advisable not to ignore it. One means of creating a "strong link" between a paper and an institution is through the "corresponding author" who takes overall responsibility for the publication process. While this is often the first-named author, this is not universal.

For our purposes, we limited our sample set to journal articles with a Digital Object Identifier (DOI) published in 2017 that included at least one author affiliated with a New Zealand university. This provided a comprehensive dataset representing a large proportion of the research outputs of all eight universities in the country. Although we were carrying out the work in 2019 we chose to use 2017 as our sample set because, firstly, the research outputs were more likely to have passed the date for embargo set by publishers for self-archiving (one of our key interests) and, secondly, citation counts would be more mature than for more recent research. 
271 DOIs for 2017 journal articles were gathered from each university, then amalgamated into a 272 single file of more than 12,600 journal articles. If there was a local corresponding author at any

273 university for a given article then it was designated as having a New Zealand corresponding

274 author. During the course of the project we found that a small percentage of articles with large

275 numbers of authors and large numbers of citations skewed the data so articles with more than 20

276 authors were excluded on the grounds that they had a tenuous connection to the New Zealand

277 University that had submitted the DOI. This reduced the sample size to 12,016. These were fed

278 into The Program.

279

280

281

282

283

284

285

286

287

288

289

290

291

292

293

294

295

296

297

298

299

300

301

302

303

304

305

306

307

308

309

\section{The Program}

At the heart of our work was the 'Program', written in Python. One of our primary aims in publishing this paper is to share the code for the Program for others to use as well as detailing the results of our own work. The code is available here: https://github.com/bruce-white-mass/conzuloa-project

A set of DOIs can be submitted to the Program, which uses a number of APIs to produce a set of results, whether for a single department, an institution, a discipline, a country (as in our case) or any other parameter. For our project, having compiled our list of DOIs as described above, we fed them into the Program using a Comma Separated Value file (.CSV). For each article the following information was obtained from a range of sources as shown in Table 2.

Errors are reported by the Program where information could not be found, for example if a DOI was not recognised.

DOIs were obtained from the individual universities. It was then possible to "chain" the data gathering. For example, Unpaywall provided ISSNs which were then submitted via API requests to Sherpa/Romeo to capture data on publisher allowances for the use of publications in institutional repositories. ISSNs were also used to capture data on APCs for individual journals.

However, not all the data used by the Program was accessible through APIs. Crossref was an excellent source of information for authors, even when these numbered in the thousands, but provides very limited data on author affiliations. On the other hand, Web of Science and Scopus provide detailed author-affiliation data, including identifying corresponding authors, but this needed to be output manually as CSV files for subsequent access by the program. A similar process was followed with APC data.

While this paper is focused on the national picture for New Zealand, for those who may be interested in utilising our code on their own DOIs we note that author affiliation data is included in the output. Therefore results can also be broken down to analyse subsets at the level of individual institutions. 
311 The process described here is also presented in Figure 1.

\section{Results}

313 The Program was run on 30 May 2019. The output was analysed and the following information 314 extracted:

315

- the overall percentage of open and closed papers both for all authors and the subset of New Zealand corresponding authors;

- the total percentage of papers in each of the access categories: Closed, Gold, Hybrid, Bronze, Green, Diamond (note that the "best version" is reported so there was no overlap between categories.);

- the total percentage of papers available through repositories (note that because an article can be published and in a repository there is some overlap with the other categories);

- the total percentage of open and closed papers funded by major New Zealand agencies;

- the total cost for Gold and Hybrid papers if all APCs had been charged as advertised;

- the total cost of APCs as advertised if they had been paid on papers available in repositories;

- the total number of closed papers that could be made open as Author Accepted Manuscripts (AAM) as deduced from allowances recorded in Sherpa/Romeo;

- the total cost of APCs as advertised if these papers were made open in Hybrid mode.

\section{Overall proportion of open v closed articles}

332

333

334

335

336

337

Overall 59\% of all the articles in our sample set were only available behind a subscription paywall (see Table 3).

When we performed the same analysis of those articles where the corresponding author was affiliated with a New Zealand university (as opposed to any of the authors being from a New Zealand university) we found the proportion of open articles was significantly less (see Table 4). The proportion of open here reduced to $34 \%$, meaning only 1 in 3 articles from 2017 where the corresponding author was affiliated with a New Zealand university was freely accessible.

\section{Articles by type of access}

As seen in Table 5, APC-incurring Gold open access comprises the largest proportion of open articles in our sample (35\% of open articles and $14 \%$ of all articles). Green is next (26\% of open articles or $10 \%$ of all articles), closely followed by Bronze. Hybrid is a significantly lower 
344 percentage with only $13 \%$ of open articles or $5 \%$ of all articles. Diamond clearly is not

345 commonly used by New Zealand researchers.

346

347 It is worth noting the 'overlap' of publications available in a published OA form with repository

348 versions. As detailed in our materials and methods section, we categorise types of OA using the

349 Unpaywall method, which assigns a single type of OA to each publication and favours the

350 published version over a Green one. While we report the proportion of Green-only OA in our

351 sample as $10 \%$ or 1256 publications, we also investigated the number of publications that are

352 available in Green and one of the other open forms: 3319 of 11993 (28\%) total papers were

353 available via a reputable repository. 2172 articles were available openly via the publisher and

354 also via a repository, representing a considerable overlap. Of particular interest is the Bronze

355 category, since these publications are of uncertain status and could revert to Closed. We found

356 that 288 of 1089 Bronze papers in Table 5 were also available via a repository, meaning those

357 would remain open even if the published version became Closed. If we add those 288 to our

358 Green-only subset then the Green proportion would increase from $10 \%$ to $13 \%$ and Bronze

359 would reduce from $9 \%$ to $7 \%$.

360

361 We were also interested to determine how many publications were only available via a New

362 Zealand university repository. Our dataset provides the URL for the repository version and by

363 filtering for the string '.ac.nz' (common to all eight New Zealand university repositories) we

364 found that a total of 125 of the 1256 Green publications (10\%) were only open because of that

365 deposit. In other words the other $90 \%$ were available either as a published open version or in a

366 non-New Zealand institutional or discipline-specific repository.

367

368

Again we analysed the subset of articles where a New Zealand university researcher was the

369

370

371

372

corresponding author for the article (see Table 6).

The pattern is broadly similar to the dataset for all authors (as seen in Table 5). Gold is most common (39\% of the open subset and 13\% of all articles); Green and Bronze are near-equal at

373 $24 \%$ and $23 \%$ respectively of the open articles and $8 \%$ of all articles; Hybrid is somewhat lower here, with $8 \%$ of open and just $3 \%$ of the total. Diamond is constant at $2 \%$ of all articles.

\section{Citation rates}

376 We examined the publications in our dataset for the number of citations reported by Crossref and 377 broke these down by the different types of access.

Each category of access contains a large number of outliers, that is, publications that were cited well above average for each access category. Also of note, publications with no citations at all were also very high for Diamond (47\%), compared with Bronze (34\%), Closed (25\%) - each of these sitting on zero of the $\mathrm{Y}$ axis in our boxplot - and with the remaining categories closely 
383 grouped (Hybrid 20\%, and Gold and Green together on 18\%). In general, Figure 2 suggests a 384 slightly higher rate of citation for open types of access compared to Closed, though one type 385 Diamond - performs the lowest in terms of citations. Table 7, which provides the standard error 386 and the confidence interval of the mean for each category, reinforces Diamond as an outlier and 387 higher rates of citation for the Green and Hybrid.

\section{Gold and Hybrid costs}

389 We extrapolated the total number of articles that might have incurred an APC by adding together

390

391

392

393

394

395

396

397

398

399

400

401

402

403

404

405

406

407

408

409

410

411

\section{Embargo periods and self-archiving}

413 Sherpa/Romeo data let us examine which of the Closed articles could be self-archived according 414 to publishers' policies. Table 9 shows, for all New Zealand-corresponding authors, when a

415 Closed article may be deposited in an institutional repository after an embargo set by the 416 publisher.

417

418 We ran the Program in mid-2019, meaning any embargo period of 18 months or less would have 419 expired. 3089 articles could have been archived but were Closed, representing $88 \%$ of all the 
420 Closed articles $(\mathrm{n}=3501)$ in our sample set. If all of these were deposited then the overall open

421

422

423

424

425

426

427

428

429

430

431

432

433

434

435

436

437

438

439

440

proportion would catapult from $41 \%$ to $67 \%$. A further 212 articles have an embargo period of two years or more. It is worth noting that 12 months is by far the most common length of embargo period but also that for almost one-fifth there is no embargo. As we have noted above in the 'Articles by type of access' section, deposit in a New Zealand university repository only made the difference between open and Closed for 125 publications.

As a result we were also able to estimate a 'theoretical' cost of APCs under the Hybrid option for papers that could have been made open as accepted manuscripts. The total comes to just under US\$8 million.

Also of interest is that 114 of the 3089 articles that could have been deposited in a repository (3.7\%) the publisher allowed the published version to be used, as opposed to the accepted manuscript.

The above calculations only consider publications where the corresponding author was from a New Zealand university, since the corresponding author is the most likely to have an accepted manuscript for deposit. However, if we extend our examination of Closed articles that could be deposited to all corresponding authors, again $88 \%$ have passed the embargo expiry date, which would mean 6204 of all the 7056 Closed papers could be placed in a repository. This would mean $93 \%$ of 2017 publications would be freely accessible without payment.

\section{Articles funded by New Zealand's major funding agencies}

Funder information from Web of Science and Scopus enabled us to estimate how much research funded by our major funding agencies is openly available, as shown in Tables 9 and 10. As indicated in our section on the context for the study, there has been no attempt by the government or major funding agencies to adopt a co-ordinated approach to open access in universities or to provide dedicated funds to support the payment of APCs. Similarly, none of these agencies release public information about outputs funded by them or the way in which they have been published.

More than half of articles in our 2017 sample that were funded by our largest research funders are behind a paywall (55\%) - that is, this research is inaccessible to the government agencies that funded it as well as to the New Zealand public. Therefore, this subset of articles was more likely to be open than the total sample ( $45 \%$ open against $41 \%$ open). The Ministry for Business, Innovation and Employment has the lowest rate of open research at 35\%, while the Health Research Council of New Zealand had the highest proportion with $55 \%$ or papers open. Papers with New Zealand corresponding authors and supported by these New Zealand funders were less likely to be open (44\%) than those without New Zealand corresponding authors (49\%). Detailed figures are presented in Table 10.

PeerJ reviewing PDF | (2020:07:51535:3:0:NEW 15 Apr 2021) 
460 We can also see in Table 10 how the funded articles that are freely accessible have been made open. Gold was by far the most common means of making a work open ( $19 \%$ of all articles or $41 \%$ of all open publications); Hybrid accounted for just $5 \%$ of all articles or $11 \%$ of all open. Green made up $11 \%$ of all works or $25 \%$ of open and Diamond just $2 \%$. Bronze means, by definition, that the permanence of the remaining $9 \%$ of all articles or $21 \%$ of open works is uncertain. Combining the figures for Gold and Hybrid where the corresponding author was a New Zealand researcher, $22 \%$ of freely accessible research funded by these agencies theoretically incurred an APC. We calculated these 249 articles to cost US\$455,000 if the 'list price' was paid in each instance. This $22 \%$ compares to $14 \%$ of publications that would have incurred an APC where there was no funding from one of the major New Zealand government agencies. In other words, where work was specifically funded by one of these agencies an APC was more likely to have been paid.

472

473

Our sample set was large enough to allow comparisons with publications supported by public funding from Australia, the United States and the United Kingdom which showed substantially higher proportions of open publications for both New Zealand and non-New Zealand corresponding authors, as presented in Table 11.

\section{Discussion}

478

479

480

481

482

483

484

485

486

487

488

489

490

491

492

493

494

495

496

We found that three out of five articles with an author from a New Zealand university were only available by paying for access (59\%). This figure increases to nearly two-thirds of all articles being closed when the corresponding author is a New Zealand university researcher (66\%).

For validation of our results we looked at the Leiden ranking measure for openness. The Leiden Ranking (Centre for Science and Technology Studies 2018) uses a different method to ours, including using data from 2014-17 and including only 5 of the 8 New Zealand universities, but produces a similar result (see Table 12).

We also used the Leiden Ranking tool to measure New Zealand's proportion of open articles against a selection of other countries. We clearly see that New Zealand's proportion of research that is openly available is below that of all the others in this selection, nearly half the figure of the highest-ranked nation, the United Kingdom. This is reinforced by our analysis of publications funded by New Zealand's major funding agencies, where we can very clearly that research funded by agencies in other countries is far more likely to be openly accessible.

A huge proportion (88\%) of the Closed articles could be self-archived in line with publishers' policies and thereby made open. Our findings suggest that New Zealand researchers do not selfarchive as often as researchers elsewhere and/or that the systems for ensuring work is archived 
497 are not effective. This is despite the fact that $87 \%$ of New Zealand researchers believe that, at a

498 policy level, publicly-funded research should be free to access (Ithaka S+R 2018). Our work

499 identifies a clear gap between belief and practice.

500

501

When it comes to paid open access (Gold \& Hybrid articles), New Zealand researchers are far

502 more likely to use the Gold route ( $82 \%$ of paid open access articles were Gold). One reason for

503 this may be the higher average APC for Hybrid, which may be seen by researchers as a luxury

504 and opted for when publishing work in a prestigious journal that will garner interest within the

505 discipline and/or from the public. This would require further analysis that was beyond the scope of the present project. We estimated a total of US $\$ 1.45$ million at 2017 prices could have been spent by our researchers: US $\$ 1.17$ million of this would have been an entirely additional cost to subscriptions for Gold OA publications; US\$281 thousand would have been on Hybrid publications, a potential double-dipping cost on top of subscriptions to those same publications. As we mention in our introduction, discussion of transformative agreements with publishers is outside the scope of our paper but our data can certainly be used by libraries and institutions to estimate the costs that are potentially being paid by researchers on top of subscription costs.

513

For our methodology, using the Unpaywall categorisation of openness means Bronze articles pose something of a quandary. Bronze was introduced by Unpaywall to be able to include papers openly accessible at a given point in time, but lacking definitive licensing information. With our Program this meant, however, that later iterations using the same DOIs (not reported on in the present paper) revealed that many papers categorised as Bronze in May 2019 had reverted to Closed or had switched to Green. The Unpaywall hierarchy places Bronze above Green, since it is the published version, but there is no way of knowing which papers will become Closed if publisher paywall restrictions are reimposed and which will continue to remain accessible through repositories. Fortunately, because Unpaywall provides repository locations in addition to the primary status it is possible to identify these Bronze/Green articles, which, for our sample, constituted $26 \%$ of all Bronze Papers.

525

In terms of citations, the complicated nature of citation advantage (or disadvantage) is well documented in the literature (Gaulé \& Maystre 2011; Mikki et al. 2018; Torres-Salinas et al. 2019). As noted in our review section, research largely suggests a correlation between openness and higher citation rates, though this is difficult to quantify, given contributing factors like disciplinary differences, the choice of publication venue by researchers, or the means by which citation rates are calculated. From our analysis, it is difficult to say definitively that open access confers a citation advantage, since different approaches to the question yield different answers. Given that two different types of open perform at opposite ends of the citation spectrum - Hybrid and Diamond - this seems to support the view that consideration needs to be given to factors such as journal choice by researchers or disciplinary norms for citation rates, which are outside the scope of the current study. 
538 Nevertheless, our work does seem to support previous findings that there is a positive correlation 539 between open access and higher citations (Archambault et al. 2014; Copiello 2019; McCabe \&

540 Snyder 2014; Mikki et al. 2018; Ottaviani 2016; Piwowar et al. 2018; Piwowar et al. 2019; Wang 541 et al. 2015), though we note the number of outliers in each category that are highly-cited. One

542 interesting subset for comparison is Closed and Green access, since Green publications are those

543 that would be Closed but for an automated deposit process or a conscious decision by a

544 researcher or institution to make that work open. Our results suggest slightly higher rates of

545 citation for Hybrid and Green; Closed does appear to perform slightly below other forms of

546 access, with the exception of Diamond.

547

548

Also of note, articles that listed a major New Zealand funding agency achieved a higher overall

549

550 rate of openness than the whole sample set (45\% as opposed to $41 \%$ ). However, this is still low considering such projects are funded specifically because they are deemed to be socially or economically valuable research to pursue and therefore worthy of targeted public funding. It should also be noted that there is a good deal of variance within the individual agencies (as low as $35 \%$ to as high as $55 \%$ open), which again evidences the lack of co-ordination amongst funders, including the government, in New Zealand. We can also see that Gold and Hybrid account for $22 \%$ of papers with a New Zealand corresponding author and that it is more likely that researchers with this kind of funding publish by paying an APC.

559

As we have seen, 3089 articles that were Closed could have been deposited in a repository. This number will have increased in the time that has elapsed since we conducted our analysis and the publication of this paper, since 24-month embargoes will have also expired. This represents an interesting consideration for universities. Clearly our institutional repositories are under-utilised if only 125 publications from 2017 are the only open version available. If those 3089 Closed articles were deposited then the overall proportion of open would catapult from $41 \%$ to $67 \%$ with the Green contribution increasing from $10 \%$ to $36 \%$. A 2015 study found that the processing cost of depositing an article in an institutional repository, including the time of the author, was $£ 33$

566 (or about US\$43) (Johnson et al. 2016). Using this figure the 3,089 articles that are closed but 567 could be open would cost US\$132,870. This compares to the US\$1.45 million identified in our 568 project as potentially paid in Gold and Hybrid APCs and the amount reported by CONZUL as 569 spent in 2017 by university libraries on subscription to electronic resources, NZ\$68.5 million 570 (around US\$45 million) (Universities New Zealand 2019).

\section{Limitations of this research}

572 We reiterate that the programmatic nature of our method means this does not represent all 573 research, only articles with a DOI. Thus there will be disciplinary skews to the sample set, since 574 journal articles and DOIs are more prevalent in certain disciplines. The research could easily be 
575 expanded to incorporate book chapters or other types of work that have a DOI. Nevertheless, not 576 all research falls within the scope of our analysis.

577

578

579

580

581

582

583

584

585

586

587

588

589

590

591

592

593

594

595

596

597

598

599

600

601

602

603

\section{Conclusions}

605 In May 2019 we ran our specially-developed software to discover that about two out of every 606 five articles authored by New Zealand researchers in 2017 were freely available on the web 607 (41\%). This is the first time we have an evidence-based picture of access to research by New

608 Zealand universities with such detail since, as a result of our work, we have far more than a 609 simple overall proportion: we can investigate the ways in which work has been made accessible, 610 we can compare the citation rates for these different modes of access, we can quantify the 611 volume of works that are closed access and could be made open and we can estimate how much 612 paid forms of open access have cost. 
613

614 Since our code is publicly available, anyone can run their own set of DOIs to perform their own

615 analysis of these aspects.

616

617 Overall, we see that more New Zealand research from 2017 is behind a paywall than is freely

618 accessible (41\% freely accessible, 59\% closed). However, when the corresponding author was a

619 New Zealand researcher the open figure drops to around a third (34\%). When our major funding

620 agencies have specifically funded the research the proportion of articles that is accessible is

621 higher but still just under half is accessible without a subscription. .

622

623 Where work is freely accessible, Gold is the most likely means of achieving this at an average

624 cost of USD1,682 per article; while Hybrid is used significantly less often it comes with a higher

625 average price (USD2,558). In all the two paid methods of making research accessible comes with

626 an estimated price tag - on top of library subscription costs, of course - of USD1.45m.

627

628

629

Green open access accounted for about one-quarter of our open articles. One further avenue we

630 can investigate is where this work was archived, whether in our own university repositories or in public ones like PubMed. We found that this proportion could be greatly increased if our authors utilised the rights afforded to them by publishers to make versions of their work freely accessible

632 in non-commercial repositories. Fully 3089 (88\%) of Closed articles could be made available in

633 this way but in our 2017 sample we identified a paltry 125 articles in New Zealand's institutional repositories that made the difference between open and closed.

635

636

These findings beg several questions worthy of further research that are outside the scope of this paper. What are the barriers to self-archiving? The most likely reasons - of which we are aware from our own anecdotal experiences - are lack of time, lack of awareness of the possibility of self-archiving, confusion about copyright and embargo periods, negative perceptions of the status of author accepted manuscripts, and the lack of user-friendliness of software used to deposit works in a repository. Why do our researchers choose one mode of publication over another? Which publishers do our researchers favour when choosing open? What influences

643 them to choose to pay a Hybrid APC? Does journal impact factor play a role in decisions or in 644 citation rates? Are there disciplinary differences?

645

646 Our data can also be interrogated further than was possible within the scope of this paper. While our focus was on a national snapshot of open and closed publications, it is also possible for individual institutions to examine their own subsets of our data to determine costs and identify closed publications that could be deposited in their repositories. We have already mentioned that information garnered about APC payments can help institutions to estimate amounts paid by researchers for publishing when looking at the value of transformative publishing agreements 652 with publishers. 
653

654 What we do know is that New Zealand research is less likely to be open than research of other

655

656

657

658

659

660

661

662 Acknowledgements

663 This research formed one part of a larger project under the auspices of the Council of New

664 Zealand University Librarians. The authors acknowledge CONZUL's guidance and support.

\section{References}

666 Abediyarandi N, and Mayr P. 2019. The state of open access in Germany: An analysis of the 667 publication output of German universities. International Conference on Scientometrics \& 668 Informetrics. Rome, Italy.

669 Adie E. 2014. Attention! A study of open access vs non-open access articles. Altmetric blog. 670 Archambault É, Amyot D, Deschamps P, Nicol A, Provencher F, Rebout L, and Roberge G.

671 2014. Proportion of open access papers published in peer-reviewed journals at the European and 672 world levels-1996-2013. Available at https://digitalcommons.unl.edu/scholcom/8/2014).

673 Archambault E, Amyot D, Deschamps P, Nicol A, Rebout L, and Roberge G. 2013. Proportion

674 of open access peer-reviewed papers at the European and world levels-2004-2011. Available at

675 https://www.science-metrix.com/pdf/SM_EC_OA_Availability_2004-2011.pdf2013).

676 Archambault É, Côté G, Struck B, and Voorons M. 2016. Research impact of paywalled versus

677 open access papers. Available at

$678 \mathrm{https}: / /$ digitalcommons.unl.edu/cgi/viewcontent.cgi?referer=https://www.google.com/\&httpsredi

$679 \mathrm{r}=1$ \&article=1028\&context $=$ scholcom2016).

680 Björk BC, and Solomon D. 2015. Article processing charges in OA journals: Relationship

681 between price and quality. Scientometrics 103:373-385. DOI:10.1007/s11192-015-1556-Z

682 Bjork BC, Welling P, Laakso M, Majlender P, Hedlund T, and Gudnason G. 2010. Open access 683 to the scientific journal literature: Situation 2009. PLoS One 5:e11273.

684 DOI:10.1371/journal.pone.0011273

685 Bosman J, and Kramer B. 2019. Publication cultures and Dutch research output: A quantitative 686 assessment. Available at https://zenodo.org/record/2643360\#.Xid4X8gzaUk2019).

687 Centre for Science and Technology Studies. 2018. CWTS Leiden Ranking 2018. Available at 688 https://easy.dans.knaw.nl/ui/datasets/id/easy-dataset:970852018).

689 Copiello S. 2019. The open access citation premium may depend on the openness and

690 inclusiveness of the indexing database, but the relationship is controversial because it is 
691 ambiguous where the open access boundary lies. Scientometrics 121:995-1018.

692 DOI:10.1007/s11192-019-03221-w

693 Fraser M, White R, Richardson E, Hayes L, Howie J, White B, Angelo A, Broughton S, and

694 Fitchett D. 2019. Open Access in New Zealand universities: An environmental scan. Available at

695 https:/www.universitiesnz.ac.nz/about-universities-new-zealand/unz-committees-and-working-

696 groups/council-new-zealand-university2019).

697 Gargouri Y, Hajjem C, Lariviere V, Gingras Y, Carr L, Brody T, and Harnad S. 2010. Self-

698 selected or mandated, open access increases citation impact for higher quality research. PLoS

699 One 5:e13636. DOI:10.1371/journal.pone.0013636

700 Gaulé P, and Maystre N. 2011. Getting cited: Does open access help? Research Policy 40:1332-

701 1338. DOI:10.1016/j.respol.2011.05.025

702 Guédon JC, Kramer B, and Laakso M. 2019. Future of scholarly publishing and scholarly

703 communication: Report of the Expert Group to the European Commission. Available at

704 http://digitalcommons.unl.edu/scholcom/972019).

705 Gumpenberger C, Hölbling L, Ignacio Gorraiz J. 2018. On the issues of a "corresponding

706 author" field-based monitoring approach for gold open access publications and derivative cost

707 calculations. Frontiers in Research Metrics and Analytics 3:1-3 DOI: 10.3389/frma.2018.00001

708 Huang CK, Neylon C, Hosking R, Montgomery L, Wilson K, Ozaygen A, Brookes-Kenworthy

709 C. 2020. Evaluating institutional open access performance: Methodology, challenges and

710 assessment. BioRxiv. DOI:1011.01/2020.03.19.998336

711 Holmberg K, Hedman J, Bowman TD, Didegah F, and Laakso M. 2019. Do articles in open

712 access journals have more frequent altmetric activity than articles in subscription-based journals?

713 An investigation of the research output of Finnish universities. Scientometrics 122:645-659.

714 DOI:10.1007/s11192-019-03301-x

715 Ithaka S+R. 2018. CONZUL faculty survey: Aggregate report of findings.

716 Jahn N, and Tullney M. 2016. A study of institutional spending on open access publication fees

717 in Germany. PeerJ 4:e2323. DOI:10.7717/peerj.2323

718 Johnson R, Pinfield S, and Fosci M. 2016. Business process costs of implementing "gold" and

719 "green" open access in institutional and national contexts. Journal of the Association for

720 Information Science and Technology 67:2283-2295. DOI:10.1002/asi.23545

721 Kirkman NS. 2018. A study of open access publishing by NHMRC grant recipients Master of

722 Philosophy. Curtin University.

723 Laakso M, Welling P, Bukvova H, Nyman L, Bjork BC, and Hedlund T. 2011. The development

724

725

726

727

728

729

730

731

732

733

734

735 of open access journal publishing from 1993 to 2009. PLoS One 6:e20961.

DOI:10.1371/journal.pone.0020961

Lovén L. 2019. Monitoring open access publishing costs at Stockholm University. Insights 32. DOI:10.1629/uksg.451

Maddi A. 2019. Construction of a Normalized Open Access Indicator (NOAI). Available at https://hal.archives-ouvertes.fr/hal-02328158/document2019).

Martín-Martín A, Costas R, van Leeuwen T, and Delgado López-Cózar E. 2018. Evidence of open access of scientific publications in Google Scholar: A large-scale analysis. Journal of Informetrics 12:819-841. DOI:10.1016/j.joi.2018.06.012

Matthias L. 2018. publisher-oa-portfolios. Available at https:/github.com/lmatthia/publisher-oaportfolios2018).

736 panel of science journals. Economic Inquiry 52:1284-1300. DOI:10.1111/ecin.12064 
737 Mikki S, Gjesdal Ø, and Strømme T. 2018. Grades of openness: Open and closed articles in

738 Norway. Publications 6:1-12. DOI:10.3390/publications6040046

739 Monaghan J, Lucraft M, Allin K, Graaf Mvd, and Clarke T. 2020. 'APCs in the wild': Exploring

740

741

742

743

744

745

746

747

748

749

750

751

752

753

754

755

756

757

758

759

760

761

762

763 funding streams for an accelerated transition to Open Access. Available at https://figshare.com/articles/_APCs_in_the_Wild_Could_Increased_Monitoring_and_Consolidat ion_of_Funding_Accelerate_the_Transition_to_Open_Access_/119881232020).

Morrison H, Mondésir G, Salhab J, Villamizar C, Calvé-Genest A, and Desautels L. 2016. Open Access Article Processing Charges (OA APC) longitudinal study 2015 preliminary dataset. 2016).

Nazim M, and Zia S. 2019. Acceptance and adoption of open access publishing by researchers in India. Global Knowledge, Memory and Communication 68:148-158. DOI:10.1108/gkmc-092018-0077

New Zealand Government. 2014. New Zealand Government Open Access and Licensing framework (NZGOAL). Available at https://www.data.govt.nz/assets/Uploads/nzgoal-version-2december-2014.pdf2014).

Ottaviani J. 2016. The post-embargo open access citation advantage: It exists (probably), its modest (usually), and the rich get richer (of course). PLoS One 11:e0159614.

DOI:10.1371/journal.pone.0159614

Pinfield S, Salter J, and Bath PA. 2017. A "Gold-centric" implementation of open access: Hybrid journals, the "Total cost of publication," and policy development in the UK and beyond. Journal of the Association for Information Science and Technology 68:2248-2263.

DOI:10.1002/asi.23742

Piryani R, Dua J, and Singh VK. 2019. Open access levels and patterns in scholarly articles from India. Current Science 117:1435-1440.

Piwowar H, Priem J, Lariviere V, Alperin JP, Matthias L, Norlander B, Farley A, West J, and Haustein S. 2018. The state of OA: A large-scale analysis of the prevalence and impact of open access articles. PeerJ 6:e4375. DOI:10.7717/peerj.4375

764 Piwowar H, Priem J, and Orr R. 2019. The Future of OA: A large-scale analysis projecting open

765

766

767

768

769

770

771

772 access publication and readership. DOI:10.1101/795310

Pölönen J, Guns R, Kulczycki E, Laakso M, and Sivertsen G. 2019. Open access challenge at the national level: Comprehensive analysis of publication channels used by Finnish researchers in 2016-2017. International Conference on Scientometrics \& Informetrics. Rome, Italy.

Robinson-Garcia N, Costas R, and Leeuwen T. 2019. Indicators of open access for universities. International conference on scientometrics \& informetrics. Rome, Italy.

Robinson-Garcia N, Costas R, and Leeuwen T. 2020. Open access uptake by universities. PeerJ 8:e9410. DOI:10.7717/peerj.9410

773 Sivertsen G, Guns R, Kulczycki E, and Pölönen J. 2019. The use of Gold open access in four

774

775

776

777

778

779

780

781

782 European countries: An analysis at the level of articles. International Conference on Scientometrics \& Informetrics. Rome, Italy. p 1600-1605.

Solomon D, and Björk B-C. 2016. Article processing charges for open access publication: The situation for research intensive universities in the USA and Canada. PeerJ 4:e2264.

DOI:10.7717/peerj.2264

Suber P. 2012. Open Access. Cambridge: MIT Press.

Torres-Salinas D, Robinson-Garcia N, and Moed HF. 2019. Disentagling Gold open access. In: Glanzel W, Moed HF, Schmoch U, and Thelwall M, eds. Springer handbook of science and technology indicators, 129-145. 
783 Universities New Zealand. 2019. Submission on review of the Copyright Act 1994: Issues Paper.

784 Unpaywall. Frequently Asked Questions. Available at https://unpaywall.org/faq

785 Wang X, Cui Y, Xu S, and Hu Z. 2018. The state and evolution of Gold open access: A country

786 and discipline level analysis. Aslib Journal of Information Management 70:573-584.

787 DOI:10.1108/ajim-02-2018-0023

788 Wang X, Liu C, Mao W, and Fang Z. 2015. The open access advantage considering citation,

789 article usage and social media attention. Scientometrics 103:555-564. DOI:10.1007/s11192-015-

$790 \quad 1547-0$

791 Wikipedia contributors. 2020. Open access in New Zealand. Available at

792 https://en.wikipedia.org/w/index.php?title=Open_access_in_New_Zealand\&oldid=953400278. 
Figure 1

Flowchart showing process of data gathering, data sources and filtering applied to create dataset

This flowchart can be used to filter our dataset to match the subsets of information used in our analysis 


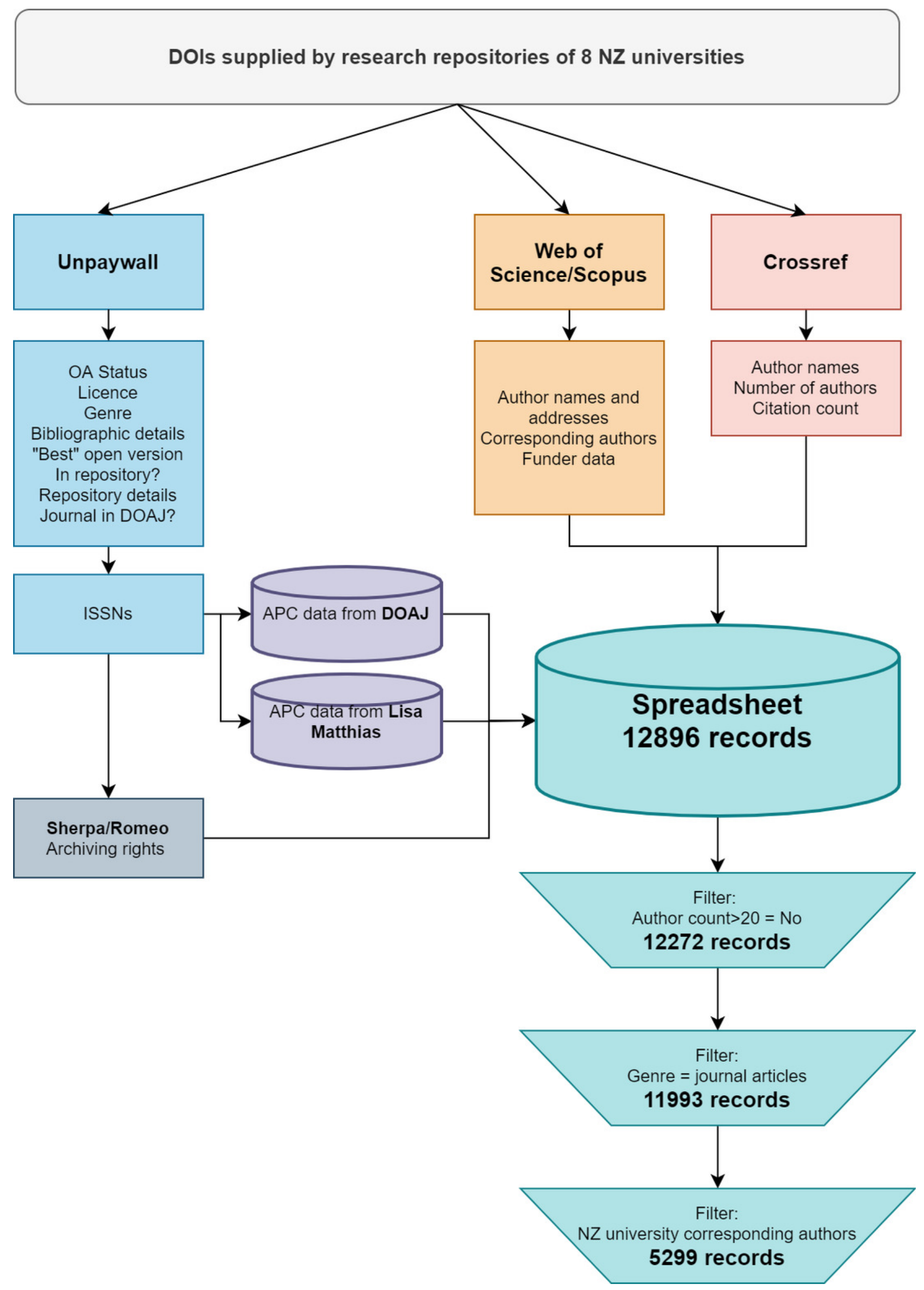




\section{Figure 2}

Crossref citations for different types of access

This boxplot compares the distribution of citations for each type of access. Citations, drawn from Crossref, are indicated on the $Y$ axis. Average citation rates for each type are indicated by the horizontal line in each box. Each category had a number of outliers (depicted as dots). The graph is cropped at 20 citations on the $Y$ axis to focus on the groupings of citations in the 0-10 range.

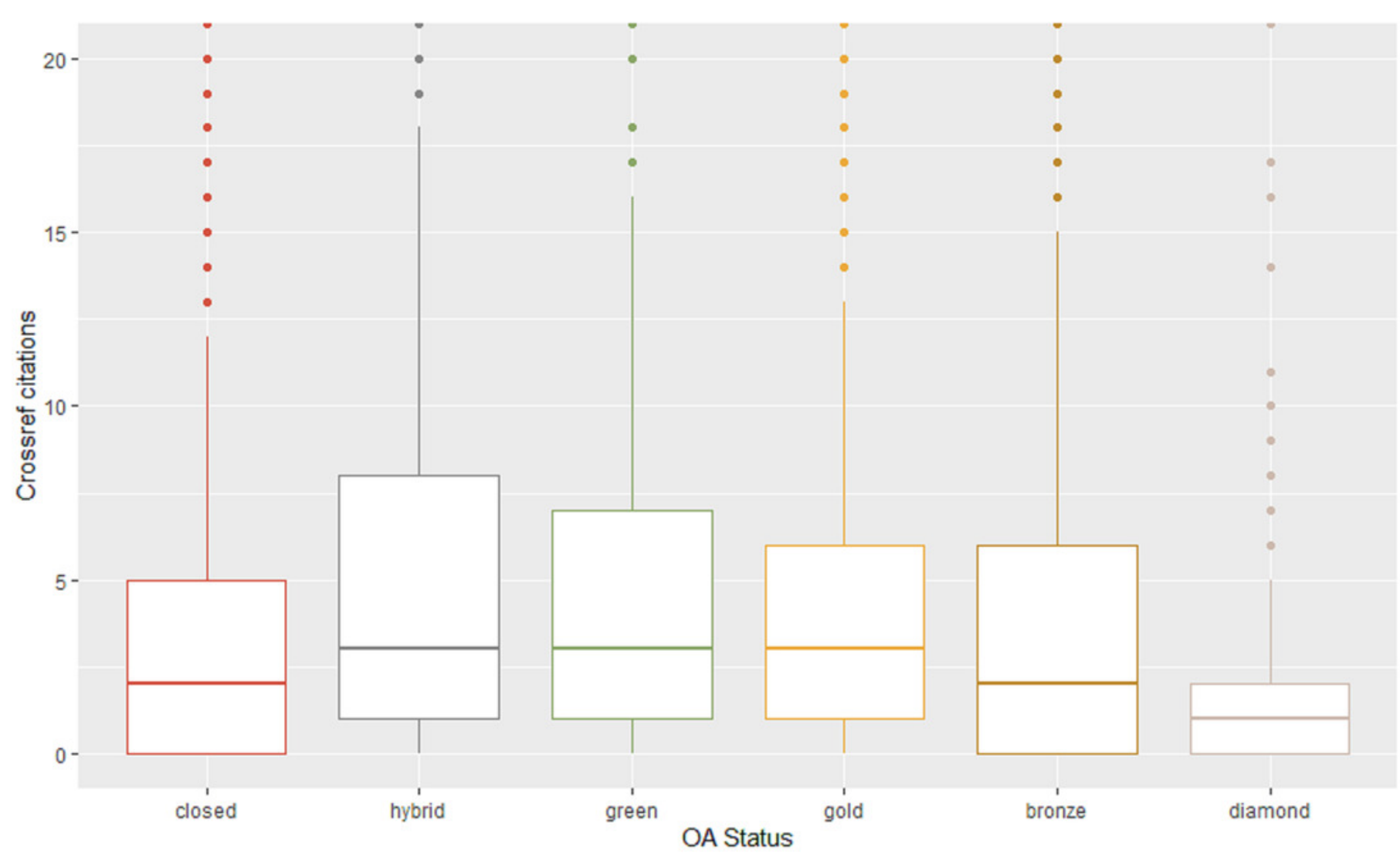


Table $\mathbf{1}$ (on next page)

Open Access Type Definition

Definitions of types of access used in this analysis 


\begin{tabular}{|l|l|}
\hline Type of Open Access & Definition \\
\hline Gold OA & Published version is immediate OA. APC charged. \\
\hline Hybrid OA & $\begin{array}{l}\text { Publication is subscription-based. APC can be paid to make } \\
\text { individual articles OA. }\end{array}$ \\
\hline Bronze OA & Currently free to read on publisher's site but licence not clear. \\
\hline Green OA & $\begin{array}{l}\text { Only accessible in a reputable repository (i.e. academic social } \\
\text { networking sites are not included). Publisher's version is paywalled. }\end{array}$ \\
\hline Closed & Published version is paywalled. \\
\hline Diamond OA & $\begin{array}{l}\text { Published version is immediate OA. Derived from Unpaywall } \\
\text { giving the status 'Gold' but where DOAJ shows no APC charged. }\end{array}$ \\
\hline
\end{tabular}


Table 2 (on next page)

Information gathered by the Program and corresponding data sources

Multiple sources of information were used in this analysis, listed here 


\begin{tabular}{|c|c|}
\hline Information & Source \\
\hline $\begin{array}{l}\text { Metadata: author(s), title, journal, } \\
\text { ISSN, etc. }\end{array}$ & Unpaywall API \\
\hline Open or closed & Unpaywall API \\
\hline $\begin{array}{l}\text { Type of access (Gold, Hybrid, } \\
\text { Green, Closed, etc.) }\end{array}$ & Unpaywall API \\
\hline Reprint/corresponding author & Web of Science and Scopus (CSV file) \\
\hline Funders & Web of Science and Scopus (CSV file) \\
\hline URLs of all repository versions & Unpaywall API \\
\hline $\begin{array}{l}\text { Type of 'best open version': } \\
\text { published, preprint, postprint }\end{array}$ & Unpaywall API \\
\hline APC/No APC & $\begin{array}{l}\text { DOAJ (CSV file) } \\
\text { GitHub site of Lisa Matthias (Freie Universität Berlin) }{ }^{1}\end{array}$ \\
\hline $\begin{array}{l}\text { Journal and publisher archiving } \\
\text { rules and embargo periods }\end{array}$ & Sherpa/Romeo API \\
\hline Citations & Crossref API \\
\hline
\end{tabular}




\section{Table 3 (on next page)}

Proportion of articles with at least one New Zealand author which were open 
1

\begin{tabular}{|l|l|l|}
\hline Availability of article & Count & \% \\
\hline Closed & 7049 & $59 \%$ \\
\hline Open & 4944 & $41 \%$ \\
\hline Total & $\mathbf{1 1 9 9 3}$ & $\mathbf{1 0 0 \%}$ \\
\hline
\end{tabular}

2 


\section{Table 4 (on next page)}

Proportion of articles which were open with a New Zealand university researcher listed as corresponding author 


\begin{tabular}{|l|r|r|}
\hline Availability of article & Count & \% \\
\hline Closed & 3501 & $66 \%$ \\
\hline Open & 1798 & $34 \%$ \\
\hline Total & $\mathbf{5 2 9 9}$ & $\mathbf{1 0 0 \%}$ \\
\hline
\end{tabular}

1 


\section{Table 5 (on next page)}

\section{Articles by type of access}

Using our definitions of types of access, the proportion of each type in our dataset is shown. This table shows all publications with at least one author affiliated to a New Zealand university. 


\begin{tabular}{|l|l|l|}
\hline Type of access & Count & \% \\
\hline Bronze & 1089 & $9 \%$ \\
\hline Closed & 7049 & $59 \%$ \\
\hline Diamond & 265 & $2 \%$ \\
\hline Gold & 1706 & $14 \%$ \\
\hline Green & 1256 & $10 \%$ \\
\hline Hybrid & 628 & $5 \%$ \\
\hline Total & $\mathbf{1 1 9 9 3}$ & $\mathbf{1 0 0 \%}$ \\
\hline
\end{tabular}

1 


\section{Table 6(on next page)}

Articles by type of access with a New Zealand corresponding author

Using our definitions of types of access, the proportion of each type in our dataset is shown.

This table shows all publications where the corresponding author is affiliated to a New Zealand university. 


\begin{tabular}{|l|l|l|}
\hline Type of access & Count & \% \\
\hline Bronze & 422 & $8 \%$ \\
\hline Closed & 3501 & $66 \%$ \\
\hline Diamond & 95 & $2 \%$ \\
\hline Gold & 697 & $13 \%$ \\
\hline Green & 432 & $8 \%$ \\
\hline Hybrid & 152 & $3 \%$ \\
\hline Total & $\mathbf{5 2 9 9}$ & $\mathbf{1 0 0 \%}$ \\
\hline
\end{tabular}

1 


\section{Table 7 (on next page)}

Standard error and confidence interval for citation rates by access type

Citations for each type of access, showing mean, median, standard deviation, standard error and confidence interval for $95 \%$ confidence level. 


\begin{tabular}{|l|l|l|l|l|l|l|}
\hline & Count & $\begin{array}{l}\text { Mean } \\
\text { Citations }\end{array}$ & $\begin{array}{l}\text { Median } \\
\text { Citations }\end{array}$ & $\begin{array}{l}\text { Standard } \\
\text { Deviation }\end{array}$ & $\begin{array}{l}\text { Standard } \\
\text { Error }\end{array}$ & $\begin{array}{l}\text { Confidence Interval } \\
(\mathbf{9 5 \% )}\end{array}$ \\
\hline Bronze & 1089 & 5.16 & 2 & 11.27 & 0.34 & $4.49,5.83$ \\
\hline Closed & 7049 & 4.53 & 2 & 9.51 & 0.11 & $4.31,4.75$ \\
\hline Diamond & 265 & 1.79 & 1 & 3.57 & 0.22 & $1.36,2.22$ \\
\hline Gold & 1706 & 5.14 & 3 & 7.75 & 0.19 & $4.77,5.5$ \\
\hline Green & 1256 & 7.54 & 3 & 26.23 & 0.74 & $6.09,8.99$ \\
\hline Hybrid & 628 & 7.50 & 3 & 15.53 & 0.62 & $6.29,8.72$ \\
\hline
\end{tabular}

1 


\section{Table 8(on next page)}

Gold and Hybrid articles

Breaks down our Gold and Hybrid articles with a New Zealand corresponding author. Where known, the total Article Processing Charges and average changes for each type are calculated. 


\begin{tabular}{|l|r|r|r|r|r|}
\hline Type of paid OA & Count & $\%$ & Known APCs & Known APC cost & Known APC avg \\
\hline Gold & 697 & $82 \%$ & 697 & $\$ 1,172,029$ & $\$ 1,682$ \\
\hline Hybrid & 152 & $18 \%$ & 110 & $\$ 281,378$ & $\$ 2,558$ \\
\hline Total & $\mathbf{8 4 9}$ & $\mathbf{1 0 0 \%}$ & $\mathbf{8 0 7}$ & $\mathbf{\$ 1 , 4 5 3 , 4 0 7}$ & $\mathbf{\$ 1 , 8 0 1}$ \\
\hline
\end{tabular}




\section{Table 9 (on next page)}

Articles that could be archived in a repository but were closed access

Shows the proportion of closed articles broken down by embargo periods listed by publishers 


\begin{tabular}{|l|r|r|}
\hline Embargo period & $\begin{array}{r}\text { Publisher policy allows accepted } \\
\text { manuscript in repository }\end{array}$ & $\%$ \\
\hline Immediate self-archive & 579 & $17 \%$ \\
\hline 3 months & 3 & $0 \%$ \\
\hline 4 months & 1 & $0 \%$ \\
\hline 6 months & 73 & $2 \%$ \\
\hline 12 months & 2115 & $60 \%$ \\
\hline 18 months & 318 & $9 \%$ \\
\hline Total archivable by mid-2019 & $\mathbf{3 0 8 9}$ & $\mathbf{8 8 \%}$ \\
\hline 24 months or more & 213 & $6 \%$ \\
\hline Not self-archivable & 199 & $6 \%$ \\
\hline Total closed articles & $\mathbf{3 5 0 1}$ & $\mathbf{1 0 0 \%}$ \\
\hline
\end{tabular}




\section{Table $\mathbf{1 0}$ (on next page)}

\section{Proportion of open articles funded by major New Zealand funders}

This table includes the New Zealand funders most represented in our dataset, showing the proportion of publications for each that are closed or open by the different methods of doing so.

The table is broken into three: it shows the results for all authors and then splits these overall figures into two subsets, where the corresponding author was a researcher affiliated with a New Zealand university and where not. 


\begin{tabular}{|c|c|c|c|c|c|c|c|}
\hline All Authors & & & & & & & \\
\hline Funder & Number & Closed & Bronze & Gold & Diam'd & Hybrid & Green \\
\hline Marsden Fund & 505 & $54 \%$ & $10 \%$ & $13 \%$ & $1 \%$ & $5 \%$ & $18 \%$ \\
\hline $\begin{array}{l}\text { Rutherford Discovery } \\
\text { Fellowship }\end{array}$ & 90 & $44 \%$ & $9 \%$ & $21 \%$ & $13 \%$ & $12 \%$ & $12 \%$ \\
\hline $\begin{array}{l}\text { Royal Society of New } \\
\text { Zealand }\end{array}$ & 714 & $54 \%$ & $9 \%$ & $14 \%$ & $1 \%$ & $6 \%$ & $16 \%$ \\
\hline $\begin{array}{l}\text { Health Research Council of } \\
\text { New Zealand }\end{array}$ & 468 & $45 \%$ & $13 \%$ & $29 \%$ & $1 \%$ & $3 \%$ & $9 \%$ \\
\hline $\begin{array}{l}\text { Ministry of Business } \\
\text { Innovation and Employment }\end{array}$ & 443 & $65 \%$ & $7 \%$ & $16 \%$ & $1 \%$ & $5 \%$ & $7 \%$ \\
\hline Total & 1519 & $55 \%$ & $9 \%$ & $19 \%$ & $1 \%$ & $5 \%$ & $11 \%$ \\
\hline \multicolumn{8}{|l|}{ NZ Corresponding author } \\
\hline Funder & Number & Closed & Bronze & Gold & Diam'd & Hybrid & Green \\
\hline Marsden Fund & 362 & $57 \%$ & $10 \%$ & $13 \%$ & $1 \%$ & $4 \%$ & $15 \%$ \\
\hline $\begin{array}{l}\text { Rutherford Discovery } \\
\text { Fellowship }\end{array}$ & 68 & $51 \%$ & $12 \%$ & $13 \%$ & $0 \%$ & $12 \%$ & $12 \%$ \\
\hline $\begin{array}{l}\text { Royal Society of New } \\
\text { Zealand }\end{array}$ & 515 & $57 \%$ & $9 \%$ & $14 \%$ & $1 \%$ & $5 \%$ & $14 \%$ \\
\hline $\begin{array}{l}\text { Health Research Council of } \\
\text { New Zealand }\end{array}$ & 356 & $46 \%$ & $13 \%$ & $29 \%$ & $1 \%$ & $3 \%$ & $8 \%$ \\
\hline $\begin{array}{l}\text { Ministry of Business } \\
\text { Innovation and Employment }\end{array}$ & 303 & $65 \%$ & $9 \%$ & $17 \%$ & $1 \%$ & $3 \%$ & $6 \%$ \\
\hline Total & 1098 & $56 \%$ & $10 \%$ & $19 \%$ & $1 \%$ & $4 \%$ & $10 \%$ \\
\hline \multicolumn{8}{|l|}{$\begin{array}{l}\text { Non-NZ Corresponding } \\
\text { author }\end{array}$} \\
\hline Funder & Number & Closed & Bronze & Gold & Diam'd & Hybrid & Green \\
\hline Marsden Fund & 143 & $45 \%$ & $9 \%$ & $12 \%$ & $1 \%$ & $7 \%$ & $25 \%$ \\
\hline $\begin{array}{l}\text { Rutherford Discovery } \\
\text { Fellowship }\end{array}$ & 22 & $23 \%$ & $0 \%$ & $45 \%$ & $0 \%$ & $18 \%$ & $14 \%$ \\
\hline $\begin{array}{l}\text { Royal Society of New } \\
\text { Zealand }\end{array}$ & 199 & $47 \%$ & $8 \%$ & $15 \%$ & $1 \%$ & $9 \%$ & $21 \%$ \\
\hline $\begin{array}{l}\text { Health Research Council of } \\
\text { New Zealand }\end{array}$ & 112 & $43 \%$ & $14 \%$ & $27 \%$ & $0 \%$ & $4 \%$ & $13 \%$ \\
\hline $\begin{array}{l}\text { Ministry of Business } \\
\text { Innovation and Employment }\end{array}$ & 140 & $64 \%$ & $4 \%$ & $14 \%$ & $1 \%$ & $9 \%$ & $8 \%$ \\
\hline Total & 421 & $51 \%$ & $8 \%$ & $18 \%$ & $1 \%$ & $8 \%$ & $15 \%$ \\
\hline
\end{tabular}




\section{Table $\mathbf{1 1}$ (on next page)}

\section{Comparison of funded articles by country}

This table shows the breakdown of access type to publications listed as funded by government funding agencies in New Zealand, the United States, Australia and the United Kingdom, showing the proportion of publications for each that are closed or open by the different methods of doing so.

The table is broken into three: it shows the results for all authors and then splits these overall figures into two subsets, where the corresponding author was a researcher affiliated with a New Zealand university and where not. 


\begin{tabular}{|c|c|c|c|c|c|c|c|}
\hline \multicolumn{2}{|c|}{ All Authors } & \multirow[b]{2}{*}{ Closed } & \multirow[b]{2}{*}{ Bronze } & \multirow[b]{2}{*}{ Gold } & \multirow[b]{2}{*}{ Diam'd } & \multirow[b]{2}{*}{ Hybrid } & \multirow[b]{2}{*}{ Green } \\
\hline Funder & No. & & & & & & \\
\hline NZ Govt & 1519 & $55 \%$ & $9 \%$ & $19 \%$ & $1 \%$ & $5 \%$ & $11 \%$ \\
\hline US Govt & 271 & $24 \%$ & $18 \%$ & $20 \%$ & $2 \%$ & $14 \%$ & $22 \%$ \\
\hline Aust Govt & 358 & $39 \%$ & $11 \%$ & $23 \%$ & $1 \%$ & $6 \%$ & $20 \%$ \\
\hline UK Govt & 199 & $12 \%$ & $17 \%$ & $27 \%$ & $1 \%$ & $20 \%$ & $24 \%$ \\
\hline \multicolumn{2}{|c|}{ NZ Corresponding Authors } & & & & & & \\
\hline Funder & No. & Closed & Bronze & Gold & Diam'd & Hybrid & Green \\
\hline NZ Govt & 1098 & $56 \%$ & $10 \%$ & $19 \%$ & $1 \%$ & $4 \%$ & $10 \%$ \\
\hline US Govt & 52 & $33 \%$ & $12 \%$ & $17 \%$ & $4 \%$ & $13 \%$ & $21 \%$ \\
\hline Aust Govt & 68 & $46 \%$ & $10 \%$ & $22 \%$ & $0 \%$ & $4 \%$ & $18 \%$ \\
\hline UK Govt & 33 & $33 \%$ & $15 \%$ & $15 \%$ & $3 \%$ & $12 \%$ & $21 \%$ \\
\hline \multicolumn{3}{|c|}{ Non-NZ Corresponding Authors } & & & & & \\
\hline Funder & No. & Closed & Bronze & Gold & Diam'd & Hybrid & Green \\
\hline NZ Govt & 421 & $51 \%$ & $8 \%$ & $18 \%$ & $1 \%$ & $8 \%$ & $15 \%$ \\
\hline US Govt & 219 & $22 \%$ & $20 \%$ & $20 \%$ & $2 \%$ & $15 \%$ & $22 \%$ \\
\hline Aust Govt & 290 & $37 \%$ & $11 \%$ & $23 \%$ & $1 \%$ & $7 \%$ & $21 \%$ \\
\hline UK Govt & 166 & $8 \%$ & $17 \%$ & $29 \%$ & $0 \%$ & $22 \%$ & $25 \%$ \\
\hline
\end{tabular}




\section{Table 12 (on next page)}

Leiden ranking proportion of open articles by country

Using Leiden Ranking data, this table lists the number of publications in eight countries and the proportion of articles that are open access 


\begin{tabular}{|l|r|r|r|}
\hline Country & \# Papers & \# OA papers & Percentage OA \\
\hline UK & 454,802 & 322,827 & $71.0 \%$ \\
\hline Norway & 42,608 & 23,109 & $54.2 \%$ \\
\hline US & $1,876,219$ & $1,013,502$ & $54.0 \%$ \\
\hline Ireland & 26,548 & 12,966 & $48.8 \%$ \\
\hline Germany & 397,439 & 190,543 & $47.9 \%$ \\
\hline Canada & 281,304 & 117,247 & $41.7 \%$ \\
\hline Australia & 273,486 & 113,789 & $41.6 \%$ \\
\hline New Zealand & 29,091 & 11,266 & $38.7 \%$ \\
\hline
\end{tabular}

1 